\title{
The Influence of Acceptability of the Roll Back Malaria Programme on Maternal Health in Ibadan, Nigeria
}

\author{
Kehinde Seun-Addie ${ }^{1}$ \\ Ezebunwa E. Nwokocha ${ }^{2}$ \\ National Population Commission ${ }^{1}$ \\ Ibadan, Nigeria \\ Department of Sociology² \\ University of Ibadan, Ibadan, Nigeria
}

DOI:10.36108/NJSA/8102/61(0240)

\begin{abstract}
The Roll Back Malaria (RBM) initiative was conceived to bolster appreciable reduction in the impact of malaria on pregnant women through Intermittent Preventive Treatment (IPT) and the use of Insecticide-treated Net (ITN). This study examines the association between knowledge and acceptability of the RBM programme on maternal health in Ibadan classified among areas with records of high prevalence of malariaimplicated maternal mortality. A survey of 407 pregnant women attending antenatal clinics at various Primary Health Centres (PHCs) in six selected Local Government Areas (LGAs) in Ibadan was undertaken. This clinic based approach was adopted to ensure that selected respondents were among those exposed to the RBM programme as antenatal care clinic attendees. Results show that increase in the knowledge of RBM related activities led to a corresponding increase in acceptability of the initiative, which ultimately led to marked improvement in maternal health. Thus, there is need to ensure that more women become aware of the RBM project as the surest trajectory for positive disposition to the RBM intervention, with a predictable concomitant improvement in maternal health status of childbearing women in Ibadan, Nigeria.
\end{abstract}

Keywords: Impact of malaria on pregnancy, antenatal care, improvement in maternal health

\section{Introduction}

The Roll Back Malaria (RBM) programme was launched in 1998 with funding from the WHO, UNICEF, UNDP and the World Bank (WHO, 2000) as an emergency response to high mortality rates in countries where individuals are exposed to female Anopheles mosquitoes. Even though it is a priority programme of the World Health Organization, other partners and multilateral agencies and governments, considering its imperativeness, have shown commitment to the initiative. It focuses on four control strategies including Case Management, use of Artemisinin-based Combination Therapies (ACTs), Insecticide-Treated Net (ITN) and other vector combination therapies that focus on malaria treatment and Intermitted Preventive Treatment (IPT) for pregnant women. It is thus embedded in preparedness and response which are critical factors for effective management of the disease. 
Nigeria is one of the countries that signed the RBM framework, thereby making it a major thrust of her national policy on malaria. Reports reveal that the progress made in the fight against malaria since the year 2000 has resulted in a 58 percent reduction in malaria related mortality, which translates to more than 6.2 million deaths that were averted between 2001 and 2015 (Schayk, 2015; WHO, 2015). This number of deaths prevented over a period of 14 years, as a result of the incursion of RBM into the disease management landscape, is by far more than the total population of Cape Verde, Gambia, Guinea Bissau and Mauritius put together (Population Reference Bureau 2017). In most malaria endemic communities, pregnant women and under-five children are particularly vulnerable and bear the heaviest burden of the disease (Adeneye et al., 2014; Nwokocha, 2014).

The effects of malaria on maternal health are multifaceted and include increased risk of miscarriage, still birth, premature birth, low birth weight, which is a leading cause of infant and child mortality. Malaria during pregnancy is also implicated in anemia which could lead to death or permanent neurological malady such as speaking disorder, epilepsy, spasticity, among others (McGready et al., 2012; Center for Disease Control (CDC), 2013; Tarning, 2016). Report shows that malaria during pregnancy accounts for 8 to14 percent of low birth weight among infants in Africa, with as high as 3 to 8 percent of these dying in areas with stable malaria transmission (WHO, 2017).

Study reports that there is transient depression of cell-mediated immunity that allows fetal allograft retention but also interferes with resistance to various infectious diseases during pregnancy (WHO, 2003). Furthermore, cellular immune responses to $P$. falciparum antigens are depressed in pregnant women, making them three times more susceptible to the disease than their nonpregnant counterparts (Okpere et al., 2010; CDC, 2013). Although P. falciparum infection in pregnancy is usually asymptomatic, it often contributes to adverse perinatal outcomes with a high risk for infant death, particularly in areas of low malaria endemicity (Tarning, 2016; WHO, 2017). Pregnancies among women living in malaria endemic regions are associated with a high frequency and density of $P$. falciparum parasitemia (WHO, 2003). This situation should ordinarily necessitate effective programming that needs to focus on the linkage between malaria control activities and antenatal care. Factors such as late commencement of antenatal care visit by pregnant women, lack of awareness about availability of malaria control services, and the notoriety of health care providers in some settings among others undermine the effectiveness of the intervention in dealing with the burden of malaria (Nwokocha, 2014; Adeneye et al., 2014). Thus, despite the introduction of the Roll Back Malaria Programme in Nigeria, a high proportion of maternal mortality is still linked to the disease (Adeneye et al., 2013).

As has been noted, malaria is both a problem of poverty and a cause of poverty (Nkegbe et al., 2017; WHO, 2017). The highest malaria mortality rates are recorded in the tropics and subtropical regions of the world with most of its countries characterized by extreme poverty (CDC, 2016). Given that malaria 
affects mostly poor women and children, it unwittingly perpetuates the vicious cycle of poverty in the developing world as a result of its spiral effects at household and community levels (WHO, 2017). As has been observed, malaria related morbidity and mortality accounts for a huge annual expenditure among relevant African countries (JHBSPH, 2018).

Although various studies have been carried out on individual components of the RBM strategy such as IPTp (Sicuri et al., 2010; Diala et al., 2013; Rassi et al., 2016) and ITN (Steinhardt, 2016; Manu et al., 2017; Taremwa et al., 2017), negligible attention has been given to issues related to knowledge, acceptability and the effect of RBM programme on maternal health.

\section{Theoretical Framework}

This study was hinged on Structural Functionalism and the Health Belief Model (HBM). The Structural Functionalist perspective views human communities as consisting of different parts or subsystems that should work collectively for the maintenance of the superstructure or the society. The interdependence of sub-units as an essential ingredient of the functioning of a system presupposes that the malfunctioning of any part of a system affects not only the affected part but also the entire structure (Ritzer, 2008). Therefore, availability of a resource, including programmes and policies, or the lack of it impinges on the functionality or dysfunctionality of the system. This perspective conceives the Roll Back Malaria initiative as basically essential in addressing a major health challenge in Nigeria and Ibadan specifically particularly among pregnant women ranked in literature among the most vulnerable groups. As such, a significant decline in maternal morbidity and mortality as a result of effective malaria reduction strategies exemplified in the RBM mechanism will largely translate to positive maternal health outcomes.

As a corollary, without that intervention (RBM), in a notoriously weak health system such as Nigeria's, several families would experience distortions arising from the death of women and mothers. Aggregation of these alterations at macro-community level will impact negatively on the proper functioning of the society generally. For instance, maternal death, in most cases, distorts the locus of household equilibrium, which may manifest in poor upbringing of young family members by the widower, disaffection between stepmothers and children left behind, large family size as the subsequent wife engages in procreation even in the midst of poverty, weak participation in economic activities and inability to defray the cost of children's education among others.

The HBM attempts to explain and predict health related behaviours by focusing on the attitudes and beliefs of individuals. The model is predicated on constructs that find expression in a prospective actor's perception that will likely drive his or her decisions about a course of action. The constructs include but not limited to: perceived susceptibility which is premised on the assumption that a person will strive to take a health related action if $\mathrm{s} / \mathrm{he}$ 
perceives that a negative health condition which the actor is prone to could be avoided; perceived severity; and a perception that the individual can successfully take a recommended health related action to improve a particular health condition if that had already occurred.

A pregnant woman is more likely to present self for malaria treatment if she perceives her likely vulnerability to the disease and the problem that will portend for her condition, as well as the likelihood of being adversely affected if not properly treated to the extent that the condition may become severe and life-threatening. Such perception could be influenced by a number of factors such as previous pregnancy experiences - by self and/or Significant Others. To be sure, awareness and information on the imperatives of the RBM project could bolster the interest of childbearing women in relevant Nigerian communities in the roll-back malaria initiative and that way increase the chances of wider acceptability of the RBM intervention.

\section{Materials and Methods}

Six Local Government Areas (LGAs) where the RBM programme was first introduced were purposively selected from the eleven LGAs in Ibadan. These included Akinyele, Egbeda, Ibadan Southwest, Ibadan Southeast, Oluyole and Lagelu LGAs. A total of 407 respondents were purposively selected based on the average monthly antenatal clinic records provided by the Primary Healthcare Centres (PHCs) in each of the LGAs. Respondents were specifically selected based on the following criteria: must be pregnant; must have registered with the clinic; and attending the antenatal clinic.

The questionnaire used in the survey comprised open-ended and closeended questions relating to variables that determine maternal health, the knowledge about malaria, and the use of its strategies such as use of insecticide treated net, use of Artemisinin-based combination therapy and intermittent preventive treatment. Being cross-sectional in design, the study utilized a mixed approach for data collection, analysis and interpretation. The data were analyzed using descriptive and inferential statistics at 0.05 level of significant. Ethical approval for the study was obtained from the Institute for Advance Medical Research and Training (IAMRAT), Ibadan, Nigeria.

\section{Result}

The majority of the respondents (82.2\%) were within 20-34yrs age bracket at the time of data collection for the study. Most of them (93.0\%) of them were married, $5.0 \%$ were single, and $1.0 \%$ were either cohabiting or separated/divorced. The age at marriage of about half of them was within 2024 years, that of $36.7 \%$ was within $25-29$ years and that of $4.2 \%$ was above 30 years of age; while $11.8 \%$ of them married as teenagers.

Table 1: Sociodemographic Characteristics of Respondents

$\begin{array}{llll}\text { Characteristics } & \text { Categories } & \text { Frequency } & \text { Percent }\end{array}$




\begin{tabular}{|c|c|c|c|}
\hline \multirow{7}{*}{ Age } & $\leq 19$ years & 17 & 4.3 \\
\hline & $20-24$ years & 80 & 20.2 \\
\hline & $25-29$ years & 158 & 39.9 \\
\hline & $30-34$ years & 90 & 22.7 \\
\hline & $35-39$ years & 45 & 11.4 \\
\hline & $40-44$ years & 6 & 1.5 \\
\hline & Total & 396 & 100 \\
\hline \multirow{6}{*}{ Marital Status } & Single Parent & 18 & 4.5 \\
\hline & Married & 377 & 93.3 \\
\hline & Cohabiting & 4 & 1.0 \\
\hline & Separated/Divorced & 4 & 1.0 \\
\hline & Others & 1 & 0.2 \\
\hline & Total & 404 & 100 \\
\hline \multirow{4}{*}{ Religion } & Christianity & 145 & 35.6 \\
\hline & Islam & 261 & 64.1 \\
\hline & Traditional & 1 & 0.2 \\
\hline & Total & 407 & 100 \\
\hline \multirow{5}{*}{ Education } & No formal education & 7 & 1.7 \\
\hline & Primary & 80 & 19.8 \\
\hline & Secondary & 226 & 55.8 \\
\hline & Post-secondary & 92 & 22.7 \\
\hline & Total & 405 & 100 \\
\hline \multirow{5}{*}{ Occupation } & Unemployed & 39 & 9.7 \\
\hline & Civil Servant & 51 & 12.6 \\
\hline & Self-employed & 299 & 74.0 \\
\hline & Others & 15 & 3.7 \\
\hline & Total & 404 & 100 \\
\hline \multirow{4}{*}{ Monthly Income (N) } & $\leq 5000$ & 43 & 51.8 \\
\hline & $5001-10,000$ & 25 & 30.1 \\
\hline & $>10,000$ & 15 & 18.1 \\
\hline & Total & 83 & 100 \\
\hline \multirow{5}{*}{ Age at Marriage } & $15-19$ years & 42 & 11.8 \\
\hline & $20-24$ years & 169 & 47.3 \\
\hline & $25-29$ years & 131 & 36.7 \\
\hline & $30+$ years & 15 & 4.2 \\
\hline & Total & 407 & 100 \\
\hline \multirow{4}{*}{ Parity } & One Pregnancy & 158 & 59.2 \\
\hline & Two Pregnancies & 88 & 33.0 \\
\hline & 4-6 Pregnancies & 21 & 7.9 \\
\hline & Total & 267 & 100 \\
\hline
\end{tabular}

Whereas 56 percent of the respondents had secondary school education, 23 percent had post-secondary education. With respect to religion, 64 percent of the respondents were practicing Islam while 36 percent were Christians. On the 
nature of employment, 13 percent of the respondents were civil servants, 74 percent were self-employed and approximately 10 percent were unemployed. Although 52 percent of the respondents reported a monthly income of $\$ 5,000$ or less, the monthly mean income was $\$ 8,519: 34 \mathrm{k}$. With respect to parity, 59 percent of the respondents stated that they had experienced one pregnancy. Those with two and three pregnancy experiences were 33 percent and 8 percent respectively.

Table 2 shows that there was a significant relationship between the knowledge of malaria and the use of RBM methods among pregnant women in Ibadan $\left(\chi^{2}\right.$ value $=21.582, \mathrm{df}=2$ and $p$-value $\left.=0.000\right)$. Given that the $\mathrm{p}$-value was less than $<0.05$, it therefore implies that the respondents' knowledge of malaria is significantly associated with the use of RBM methods, even though they did not know RBM as a programme.

Table 2:Knowledge of Malaria and use or non-use of RBM by respondents

\begin{tabular}{lllllll}
\hline $\begin{array}{l}\text { Use or non-use } \\
\text { of RBM }\end{array}$ & \multicolumn{2}{c}{ Knowledge of Malaria } & & & \\
Low & Moderate & High & Chi square & Df & P-value \\
\hline RBM & 45 & 78 & 109 & 21.582 & 2 & \multirow{2}{*}{.000} \\
No RBM & 62 & 59 & 45 & & & \\
\hline
\end{tabular}

Table 3 shows the interaction between respondents' place of delivery and the personnel that assisted with child delivery. The result $\left(\chi^{2}=221.63, \mathrm{df}=16\right.$ and $\mathrm{p}=0.000$ ) indicate a strong relationship between both variables. Clearly, place of delivery is a major determinant of the category of health personnel that attended to childbirth. For instance, it is most unlikely that a medical doctor undertakes child delivery in an unorthodox maternal health facility and vice versa.

Table 3: Respondents' Place of Delivery and Personnel that Assisted during Delivery

\begin{tabular}{l|ccccc|ccc}
\hline \multicolumn{1}{c}{$\begin{array}{c}\text { Birth } \\
\text { Attendant }\end{array}$} & $\begin{array}{c}\text { Govt } \\
\text { Hospital }\end{array}$ & $\begin{array}{c}\text { Health } \\
\text { Centre }\end{array}$ & $\begin{array}{c}\text { Private } \\
\text { Hospital }\end{array}$ & $\begin{array}{c}\text { TBA's } \\
\text { Home }\end{array}$ & Others & $\begin{array}{c}\text { Chi } \\
\text { Square }\end{array} \quad$ df & p-value \\
\hline Doctor & 22 & 3 & 32 & 0 & 2 & & & \\
Nurse & 68 & 66 & 11 & 0 & 9 & & & \\
Mid Wife & 6 & 10 & 2 & 0 & 15 & 221.63 & 16 & 0.000 \\
Relatives & 0 & 0 & 0 & 1 & 12 & & & \\
Others & 0 & 1 & 0 & 1 & 4 & & & \\
\hline
\end{tabular}

Table 4 presents data on respondents' level of education as it relates to use or non-use of the RBM strategy. The p-value of 0.131 indicates that one's level of education does not have a significant relationship with either choosing RBM or not as a strategy for managing malaria especially during pregnancy. 
Table 4: Respondents' Choice of RBM or no-RBM by Level of Education

\begin{tabular}{llllll}
\hline $\begin{array}{l}\text { Educational } \\
\text { qualification }\end{array}$ & RBM & No RBM & Chi square & df & P-value \\
\hline $\begin{array}{l}\text { No formal education } \\
\text { Primary }\end{array}$ & 4 & 3 & & & \\
Secondary & 48 & 31 & & & \\
Post-secondary & 120 & 100 & 9.848 & 6 & 0.131 \\
\hline
\end{tabular}

In order to examine the interaction between RBM and maternal health in the study area, a logistic regression analysis of the influence of knowledge of RBM methods and their acceptability on maternal health was undertaken. It is important to note that knowledge of and acceptability of RBM management approaches were critical variables used in explaining maternal health.

Table 5: Showing Logistic Regression Results for Knowledge and Acceptability of RBM and Maternal Health

\begin{tabular}{lllllll}
\hline & B & S E & & Df & Sig & ExpB \\
\hline Knowledge & 0.218 & .046 & 22.825 & 1 & 0.001 & 1.244 \\
Acceptability & 0.150 & .007 & 511.935 & 1 & 0.000 & 1.161 \\
Constant & -5.602 & .230 & 592.966 & 1 & 0.000 & 0.016 \\
\hline
\end{tabular}

The result shows that the knowledge of $\mathrm{RBM}(\mathrm{B}=0.218$, wald $=22.825, \mathrm{p}<$ $0.05)$ and its acceptability $(\mathrm{B}=0.150$, wald $=511.935, \mathrm{p}<0.05)$ contributed significantly to improvement in maternal health, given the odds ratio 1.244 and 1.161 for the knowledge of RBM methods and their acceptability respectively. Hence, in order to achieve a significant improvement in maternal health in the study area, there is need to increase the knowledge of RBM among women of reproductive age as the surest way of increasing the acceptability of RBM for prevention and treatment of malaria especially during the pregnancy-postnatal period.

\section{Discussion}

In this section we discuss some of the salient findings of the research in order to deepen understanding about issues related to knowledge and acceptability of the RBM project, which has been widely acknowledge as efficacious in malaria management not only among childbearing mothers but also the general population in malaria endemic communities (Garuba et al., 2016; Adeneye et al., 2014). Most of the respondents had some level of formal education; while only 1.7 percent did not have any form of formal education, approximately 89 percent had more than primary school certificate. Such level of education for the most part influences awareness and adaptability to new ideas or strategies. In this analysis however, adoption and/or use of RBM initiative was not 
significantly influenced by respondents' level of education. Hence, other factors such as peer group factor, awareness and advocacy strategy among others may have had greater effect on knowledge and acceptability of the RBM programme than educational status of the respondents.

As high as 10 percent of the respondents were unemployed, which considering the literacy level in the study area could be classified as high. In addition, the level of literacy does not actually reflect the occupational categories of the respondents with most of them reporting self-employment. The average monthly income of respondents was N8,519 which is the equivalent of USD 25 is to say the least extremely low to enable them meet critical family and household needs including that impinge on their health. Studies indicate that although malaria is transmitted through exposure to anopheles mosquito in communities poorly fed individuals are more susceptible to malaria due to a weaken immune system that results from poor nutritional status (Seun-Addie and Nwokocha, 2017; Nwokocha, 2014).

The findings of this study indicate that knowledge of RBM is significantly related to adoption of the RBM strategy in the study. The implication is that although the initiative was introduced over a decade and half ago, sensitization about the intervention may still be necessary in some Ibadan communities. This position is premised on the fact that awareness about RBM needs to be continuous and sustained in view of the changing nature of societies. For instance, younger women that get married and begin their reproductive activities would require sensitization related to health-seeking behavior particularly during pregnancy. It has been noted that at the inception of the RBM project in Nigeria, several mechanisms such as the mass-media and neighbourhood outreaches among others were employed educate the populace. Presently, such level of priority is not given to community awareness about RBM to the effect that some individuals neither appreciate the essence of the intervention nor utilize.

To be sure, the type of facility chosen for ANC and child delivery will determine the quality of services received by the women attending such facilities. As Ambruoso et al. (2005) observed, women expect humane, professional and courteous treatment from health professionals and a fairly standard physical environment. This is not the case of most health facilities due to excessive workload on one hand and poor maintenance culture on the other. The health facilities where the survey was conducted were heavily short-staffed and the available staff were under severe pressure. Human resources are fundamental to the functioning of a health system and are in many less developed countries a major constraint to the scaling up of health interventions.

\section{Conclusion and Recommendations}

The study has shown that maternal health will improve with adoption of the Roll Back Malaria strategy as an integral component of pregnancy and postnatal care. Embracing the initiative fully and adequately supposes exposure to appropriate knowledge of the ingredients of the intervention which is a 
precursor to its acceptability. The implication is that awareness of the RBM approach, towards reducing both the incidence and prevalence of malaria, should be widespread and central to maternal education among women of reproductive age in Ibadan, Nigeria. The critical challenge therefore is to devise mechanisms through which all categories of women could benefit from the RBM intervention irrespective of socioeconomic status, place of antenatal care and delivery and level of education. More importantly, as a way of entrenching the initiative, the components and commodities that make up the RBM project should be made consistently available to prospective beneficiaries in order to forestall relapse.

The stocking of adequate anti-malaria drugs in relevant health facilities has to be ensured by health authorities, which is a critical factor for building community confidence. This will bridge the gap related to instances whereby several patients that attend clinics are referred to other facilities to purchase prescribed drugs. The danger that such a scenario, which is key to exposure to fake and counterfeit drugs, portends for inefficacy and worsening health condition cannot be overstated and indeed erodes the very essence of the RBM intervention. We contend here that the surest way of ensuring that the strategy continues to appeal to the individuals in Ibadan communities, particularly women of reproductive age, is to make relevant RBM materials and services friendly.

\section{References}

Adeneye, A.K., Jegede, A.S., Nwokocha, E.E. and Mafe, M.A. (2014) "Perception and affordability of long lasting insecticide-treated nets among pregnant women and mothers of children under five years in Ogun State, Nigeria". Journal of Infection and Public Health, 7(6):522-533.

Adeneye, A.K., Jegede, A.S., Mafe, M.A. and Nwokocha, E.E. (2013) "Community perceptions and home management of malaria in selected rural communities of Ogun State, Nigeria". International Journal of Malaria Research and Reviews, 1(3): 22-34.

Center for Disease Control (2013) Treatment of Malaria: Guidelines for Clinicians (United States). https://www.cdc.gov/malaria/diagnosis_treatment/clinicians 3.html.

Center for Disease Control (2014) Impact of malaria. https://www.cdc.gov/malaria/malaria_worldwide/impact.html.

Center for Disease Control (2016) CDC 24/7; Saving Lives, Protecting People. Global Health - Division of Parasitic Diseases and Malaria.

D’Ambruoso, L., Abbey, M. \& Hussein, J. (2005) Please understand when I cry out in pain: women's accounts of maternity services during labour and delivery in Ghana. BMC public health, 5(1): 140. 
Diala, C.C., Pennas, T., Marin, C. and Belay, K.A. (2013) Perceptions of intermittent preventive treatment of malaria in pregnancy (IPTp) and barriers to adherence in Nasarawa and Cross River States in Nigeria. Malar J. 2013; 12: 342. Published online 2013 Sep 23. doi: 10.1186/1475-287512-342. PMCID: PMC3849531.

FMoH (2005) Federal Ministry of Health: National Malaria Control Programme in Nigeria. Annual report, 2005. Abuja, Nigeria.

Garuba, S.A.; Nwokocha, E.E.; Iruaga, E. and Nyiakaa, S.S. (2016) "Socioeconomic Context of Water, Sanitation and Hygiene Practices in Delta, Edo and Ekiti States, Nigeria". The Nigerian Journal of Sociology and Anthropology, 14(1): 1-19.

JHBSPH (2018) Malaria. Voices for a Malaria-Free Future, John Hopkins Bloomberg School of Public Health, Center for Communication Programmers'. https://www.malariafreefuture.

Manu, G., Boamah-Kaali, E.A., Febir, L.G., Ayipah, E., Owusu-Agyei, S. and Asante, K.P. (2017) Low Utilization of Insecticide-Treated Bed Net among Pregnant Women in the Middle Belt of Ghana, Malaria Research and Treatment, vol. 2017, Article ID 7481210, 7 pages, 2017. doi:10.1155/2017/7481210.

McGready, R., Lee, S.J., Wiladphaingern, J. et al. (2012) Adverse effects of falciparum and vivax malaria and the safety of antimalarial treatment in early pregnancy: a population-based study. Lancet Infect Dis, 12: 388-396.

Nkegbe, P.K., Kuunibe, N., Sekyi, S. and Aye, G. (2017) Poverty and malaria morbidity in the Jirapa District of Ghana: A count regression approach, Cogent Economics \& Finance, 5:1, DOI: 10.1080/23322039.2017.1293472.

Nwokocha, E.E. (2014) "Adherence to malaria treatment during pregnancy: Do availability and utilization of medical facilities translate to compliance?" Gender and Behaviour, 12(2): 6329-6340.

NMCP/FMOH (2006) Federal Ministry of Health, National Malaria Control Programme; A 5-year Strategic Plan: 2006-2010.

Okpere, E.E., Enabudoso, E.J. and Osemwenkha, A.P. (2010) Malaria in Pregnancy. Niger Med J, 51: 109-13.

Population Reference Bureau (PRB) (2017) World Population Data Sheet. Washington D.C: Measure Communication.

Rassi, C., Graham, K., King, R., Ssekitooleko, J., Mufubenga, P. and Gudoi S.S. (2016) Assessing demand-side barriers to uptake of intermittent preventive treatment for malaria in pregnancy: a qualitative study in two regions of Uganda. Malaria Journal 201615:530. https://doi.org/10.1186/s12936-016-1589-7.

Ritzer, G. (2008) Sociological Theory, Seventh Edition. Boston: McGraw-Hill.

Schayk, Ingeborg van (2015) Roll Back Malaria Partnership releases new strategies to guide global efforts toward malaria elimination by 2030 . https://www.malariaworld.org. 
Seun-Addie, F.K. and Nwokocha, E.E. (2017) The Influence of Roll Back Malaria Program on Knowledge of Malaria among Pregnant Women in Ibadan, Nigeria. The Nigerian Journal of Sociology and Anthropology, 15(1): 118-138.

Sicuri, E., Bardají, A., Nhampossa, T., Maixenchs, M., Nhacolo, A., Nhalungo, D. et al. (2010) Cost-Effectiveness of Intermittent Preventive Treatment of Malaria in Pregnancy in Southern Mozambique. PLoS ONE 5(10): e13407. doi:10.1371/journal.pone.0013407.

SMOH (2012) Ogun State Ministry of Health. Malaria Control Activities Report.

Steinhardt, Laura C et al. (2016) Effectiveness of insecticide-treated bednets in malaria prevention in Haiti: a case-control study. The Lancet Global Health, 5(1): e96 - e103.

Taremwa, I.M., Ashaba, S., Adrama, H.O., Ayebazibwe, C., Omoding, D., Kemeza, I., Yatuha, J., Turuho, T., MacDonald, N.E. and Hilliard, R. (2017) Knowledge, attitude and behaviour towards the use of insecticide treated mosquito nets among pregnant women and children in rural Southwestern Uganda. BMC Public Health. 17: 794. Published online 2017 Oct 10. doi: 10.1186/s12889-017-4824-4. PMCID: PMC5634848.

Tarning, Joel (2016) Treatment of Malaria in Pregnancy. N Engl J Med, 374: 981-982. DOI: 10.1056/NEJMe1601193.

WHO (2000) WHO Expert Committee on Malaria. Twentieth report. Geneva, (WHO Technical Report Series, No.892).

WHO (2003) The African Malaria Report 2003. Geneva, Switzerland. http://apps.who.int/iris/bitstream/10665/67869/1/WHO_CDS_MAL_2003.1093. pdf.

WHO (2009) World Malaria Report 2009. Geneva, Switzerland: World Health Organization. Available at http://www.who.int/malaria/world malaria report 2009/en/index.html.

WHO (2015) Action and Investment to defeat Malaria 2016-2030. For a Malaria-Free World. I.World Health Organization. ISBN 978924150897 1.

WHO (2017) Malaria in pregnant women. http://www.who.int/malaria/areas/high_risk_groups/pregnancy/en/.

WHO (2017) World Malaria Report 2017. World Health Organization, Geneva, Switzerland. ISBN; 978-92-156552-3. 